\title{
The Rate of Caesarean Sections in Burkina Faso's Regional and University Hospitals According to the Classification System of Robson's Ten Groups
}

\section{Adama Ouattara ${ }^{*}$, Sibraogo Kiemtoré1, Issa Ouédraogo², Yobi Alexis Sawadogo ${ }^{1}$, Tieba Millogo ${ }^{3}$, Mady Bikienga², Seni Kouanda ${ }^{3}$, Charlemagne Marie Ragnang-Newendé Ouédraogo ${ }^{1}$}

\author{
${ }^{1}$ Department of Gynecology-Obstetrics of the UFR/SDS of the Joseph KI ZERBO University, Ouagadougou, Burkina Faso \\ ${ }^{2}$ Gynecology-Obstetrics Department of CHU-Ouahigouya, Burkina Faso \\ ${ }^{3}$ African Institute of Public Health, Burkina Faso \\ Email: *ouattzangaadama@yahoo.fr
}

How to cite this paper: Ouattara, A., Kiemtoré, S., Ouédraogo, I., Sawadogo, Y.A., Millogo, T., Bikienga, M., Kouanda, S. and Ouédraogo, C.M.R.-N. (2021) Paper Title. Open Journal of Obstetrics and Gynecology, 11, 210-219.

https://doi.org/10.4236/ojog.2021.112021

Received: November 1, 2020

Accepted: February 23, 2021

Published: February 26, 2021

Copyright $\odot 2021$ by author(s) and Scientific Research Publishing Inc. This work is licensed under the Creative Commons Attribution International License (CC BY 4.0).

http://creativecommons.org/licenses/by/4.0/

\begin{abstract}
Background: Quality assurance in labor and delivery is needed. The method must be simple and consistent, and be of universal value. The 10-Group Classification System is a simple method providing a common starting point for further detailed analysis within which all perinatal events and outcomes can be measured and compared. Objective: The purpose of this study was to analyze cesarean section (CS) rates using the classification system of Robson's ten groups and to identify the main contributors to the overall CS rate in Burkina Faso's regional and university hospitals. Materials and Method: A cross-sectional study with retrospective collection was carried out. All women who gave birth between July 1, 2017 and June 30, 2018, in the Regional Hospital Centres (RHC) and University Hospital Centres (UHC) of Burkina Faso were classified according to the Robson ten-group method. The overall CS rates and in each Robson group were calculated, as well as the contribution of each group to the overall CS rate. Results: The CS rate was 26.5\% (8543 out of 32,240 deliveries) during the study period. nulliparous women with single term pregnancy in cephalic presentation during spontaneous labour (group 1), multiparous women with single pregnancy in cephalic presentation, gestational age $\geq 37 \mathrm{SA}$, spontaneous labour (group 3) and multiparous women with previous CS (group 5) were the main contributors (67.7\%) to the overall CS rate. In addition, we observed a variation in CS rates between different hospitals, especially among women with full-term pregnancies in cephalic presentation without previous CS (groups 1 to 4), showing large differences
\end{abstract}


in emergency obstetric and neonatal care across the country. Conclusions: Women in groups 1, 3 and 5 were the most important contributors to the overall CS rate in Burkina Faso. It appears that efforts to reduce the overall rate of CS should focus on vaginal delivery on the scarred uterus, reduction of CS rates in nulliparous women with full-term pregnancy in cephalic presentation (groups 1) and proper monitoring of multiparous women with full-term pregnancy in spontaneous labour (group 3).

\section{Keywords}

Caesarean Section, Robson's Group, Burkina Faso

\section{Introduction}

Caesarean section is the most common obstetric intervention and in some high-income countries has reached epidemic levels. The WHO states that the frequency of CS from more than $10 \%$ to $15 \%$ is unjustified [1]. However, the summary data from several countries showed the increase in CS rates from $14 \%$ of all births in 1990 to nearly $20 \%$ in 2000 and $26 \%$ in 2009 [2]. In recent years, CS rates in Finland were 15.7\%; in Denmark 20.6\%; in Ireland 26\%; in Italy 38.4\%; and even $42.7 \%$ in Turkey [2]. The population CS rate in Burkina Faso increased more than 1.5 times, from $1.2 \%$ in 2005 to $2 \%$ in 2017 [3].

Rising rates of CS are becoming a major public health problem and the factors that cause this phenomenon and strategies to reduce cesarean birth are being intensively analyzed [4] [5] [6]. However, in order to propose and implement effective measures to reduce SC, it was first necessary to identify the groups of women who experience SC and study the underlying reasons in the local context.

The audit of CS rates was carried out in many countries, regions and hospitals, comparing indications in some groups of women [7] [8]. However, the many methods and classifications used had quickly shown their limitations.

In 2001, Robson introduced a new classification system called the classification of Robson's ten groups [9]. The latter met current international and local standards for auditing and comparing CS rates of different parameters and, most importantly, helping to create and implement effective strategies specifically targeted to optimize the CS rate [10].

From this recommendation, authors reported varying results depending on the continent and the work environment. In Brazil, groups 5, 1 and 3 contributed the most to the cesarean section rate [11]. In Bosni Herzegovina, it was more the groups 2, 1 and 5 [12] while in Lithuania, it was the group 1, 2 and 5 [13].

In Burkina Faso, so far, the CS classifications used have been based on indication and urgency. Increasingly, providers were asked to consider organizing their data according to Robson's classification [14] [15]. The objective of this study was to analyze birth rates by CS using Robson's classification and identify the main contributors to the overall CS rate in Burkina Faso's regional and uni- 
versity hospitals according to the classification system of the ten Robson groups.

\section{Material and Method}

All birth surveillance hospitals in Burkina Faso were invited to participate in a retrospective cross-sectional study, which was conducted from 1 July 2017 to 31 June 2018. A Working Group on Caesarean section has been set up by the Society of Gynecologists and Obstetricians of Burkina Faso (SOGOB). Exchanges were held between the different providers to harmonize the study protocol and the concept of Robson classification. If a head of the obstetrical gynecology department was unable to attend the meeting, all information and an invitation to participate in the study was sent by email and discussed by phone. The consent of all department heads was obtained before the study began.

In total, 08 Regional Hospital Centres (RHCs) and 03 University Hospital Centres (UHCs) with maternity participated in the study and their obstetrical cohorts represented the study group consisting of 32,240 births $(61.3 \%$ of all births in Burkina Faso). Important aspects in Robson's classification are the presentation of the fetus (cephalic, breech), the number of fetuses (singleton, multiple pregnancy), obstetrical history (nulliparous, multiparous with or without CS history), labour and delivery course (spontaneous or induced preparatory labour or scheduled pre-labour) and gestational age (premature or term) (9). Based on these parameters, all women were assigned to one of the 10 groups (Table 1) [9].

The summary data of the different structures were collected and transmitted by e-mail by the interviewers who were trained before the start of the survey. The main investigator and his deputy provided ongoing training not only before the study but also throughout the survey process (personally, by e-mail or by telephone) when difficulties arise in classifying women. These efforts have been made to avoid misclassification.

Table 1. Distribution of Caesarean section indications by Robson's 10 groups [9].

\begin{tabular}{cc}
\hline Group & Classification \\
\hline 1 & Nulliparous, single cephalic, $\geq 37$ weeks in spontaneous labour \\
2 & Nulliparous, single cephalic, $\geq 37$ weeks induced (including prelabour SC) \\
3 & Multiparous, single cephalic, $\geq 37$ weeks, (excluding SC), in spontaneous labour \\
4 & Multiparous, single cephalic, $\geq 37$ weeks, induced labour or SC before labour \\
5 & Multiparous, single cephalic, $\geq 37$ weeks, previous CS \\
6 & All nuliparous breech \\
7 & All multiparous breech (including previous CS) \\
8 & All multiple pregnancies (including previous CS) \\
9 & All transverse or oblique lie (including previous CS) \\
10 & All preterm single cephalic, $\leq 37$ weeks (including previous CS) \\
\hline
\end{tabular}


Cesarean section data from each hospital were analyzed using the Robson classification system with reference to the overall cesarean section rate, the size of each group, the cesarean section delivery rate in each individual group, and the contribution of each group to the total cesarean section delivery rate.

The method of calculating each group's contribution to the overall Caesarean section rate is presented in Table 2.

The data were processed using a software package SPSS 15.0 for Windows. The study was approved by the Health Ethics Committee.

\section{Results}

\subsection{Cesarean Rate}

A total of 8543 caesarean sections were performed among 32,240 deliveries, for an overall average CS rate of $26.5 \%(21.56 \%-43.8 \%)$. The distribution of the cesarean section rate according to the hospital is presented in Table 3.

During the same period, deliveries in hospitals accounted for $61.3 \%$ of all deliveries in the country.

\subsection{Robson Classification System}

The distribution of each Robson group's contribution by structure to the overall cesarean section rate was presented in Figure 1.

In all hospital settings, Groups 3, 1 and 5 were the largest groups representing more than $75 \%$ of cesarean section indications.

Groups 6 to 10 accounted for about a quarter of deliveries in both university and regional hospitals.

Table 2. How the Caesarean section rate is calculated according to "Robson" groups.

\begin{tabular}{ccccc}
\hline $\begin{array}{c}\text { Robson" } \\
\text { Group }\end{array}$ & $\begin{array}{c}\text { Number of } \\
\text { women in } \\
\text { labour (A) }\end{array}$ & $\begin{array}{c}\text { Number of } \\
\text { Caesarean } \\
\text { sections }(\mathrm{B})\end{array}$ & $\begin{array}{c}\text { Caesarean } \\
\text { section rate }(\%) \\
\text { B/A }\end{array}$ & $\begin{array}{c}\text { Contribution } \\
\text { to the overall } \\
\text { rate (\%) (B/C) }\end{array}$ \\
\hline 1 & A1 & B1 & B1/A1 & B1/C \\
2 & A2 & B2 & B2/A2 & B2/C \\
3 & A3 & B 3 & B3/A3 & B3/C \\
4 & A4 & B4 & B4/A4 & B4/C \\
5 & A5 & B5 & B5/A5 & B5/C \\
6 & A6 & B6 & B6/A6 & B6/C \\
7 & A7 & B7 & B7/A7 & B7/C \\
8 & A8 & B8 & B8/A8 & B8/C \\
9 & A9 & B9 & B9/A9 & B9/C \\
10 & A10 & B10 & B10/A10 & B10/C \\
Total & (C) & & & \\
\hline
\end{tabular}


Table 3. Distribution of Caesarean section rates according to the hospital.

\begin{tabular}{ccc}
\hline Hospital & Number of deliveries & Cesarean rate \\
\hline Ouaga & 7152 & 21.5 \\
CHU SS & 4149 & 25.70 \\
CHRU OHG & 2501 & 28.6 \\
CHR Gaoua & 2358 & 35.19 \\
CHR Kaya & 2441 & 43.8 \\
CHR Dori & 2647 & 28.2 \\
CHR Tenko & 2336 & 36 \\
CHR KDG & 2284 & 34.7 \\
CHR DDG & 2268 & 32.2 \\
CHR Fada & 2003 & 23.8 \\
CHR Banfora & 2101 & 31.6 \\
Total & 32,240 & 26.5 \\
\hline
\end{tabular}

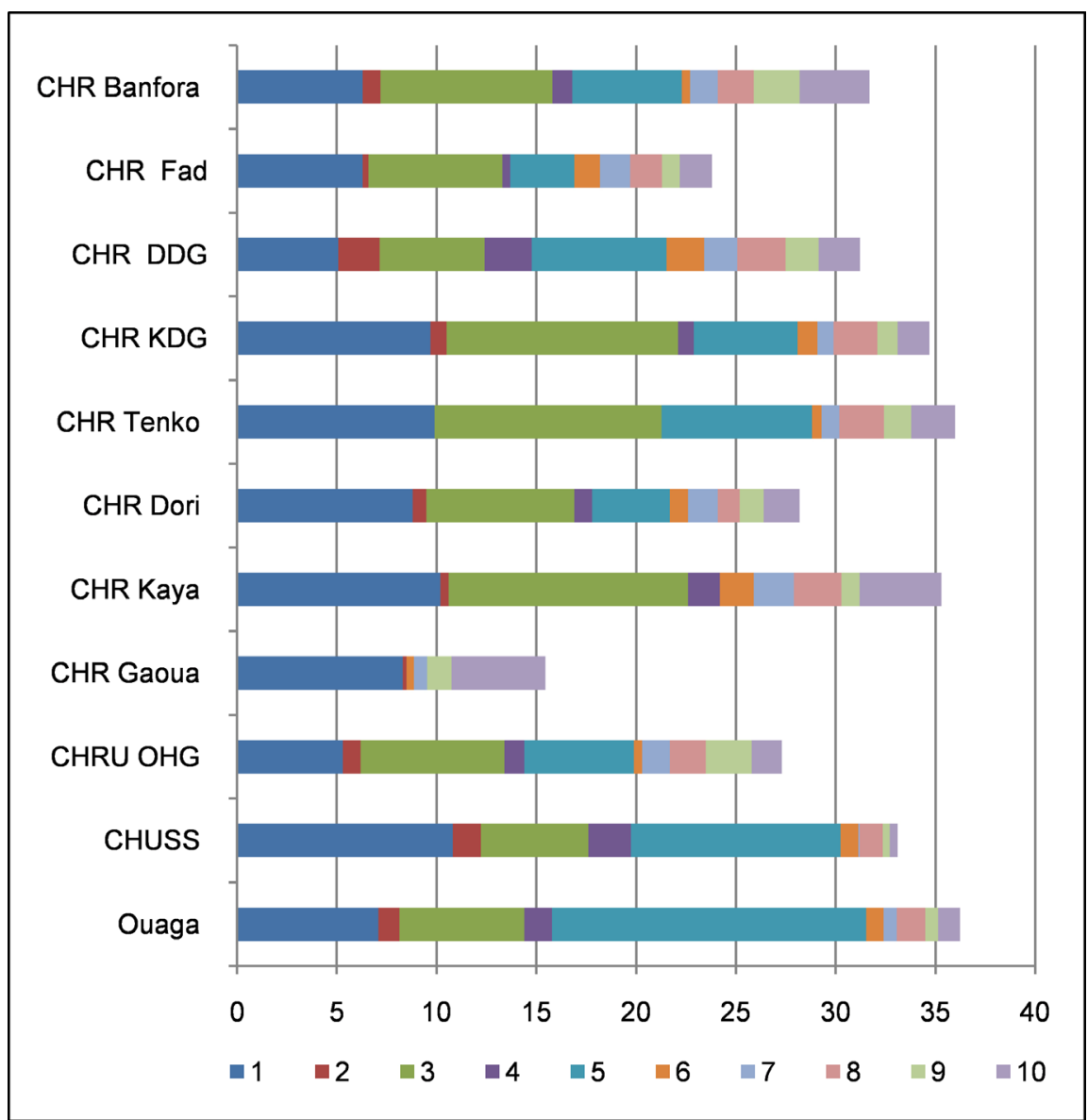

Figure 1. Contribution of each of the ten ROBSON groups to the overall Caesarean section rate and by care facility. 
Analysis of the CS rates in each individual group showed variation in the CS rate between university and non-university structures. The distribution of the contribution to the overall Caesarean section rate by type of structure is presented in Table 4.

The Caesarean section rate was $33.3 \%$ in regional hospitals and $25.1 \%$ in university hospitals respectively. In both categories of structures, Groups 3, 1 and 5 contributed $70.2 \%$ of the overall CS rate in Regional Hospital Centres and 85\% in University Hospitals (Table 4).

\section{Discussion}

\subsection{Study Limits}

Our study was carried out in public healthcare hospitals, as private hospitals could not be taken into account. This could constitute a limitation in the extrapolation of our conclusions. It was the same, about the diversity of the practitioners posing the indications of Cesarean. Despite these limitations, we have achieved interesting results which deserve a comparison with those of the literature.

\subsection{Cesarean Rate and Robson Classification}

The analysis of more than 32,240 deliveries ( $61.3 \%$ of all deliveries during the study period) in 11 health care institutions showed that groups 3, 1 and 5 were the largest contributors to the overall CS rate and accounted for two thirds of the total CS rate in Burkina Faso. In addition, the CS rate in nulliparous women

Table 4. Distribution of Caesarean section contribution rates by type of hospital and Robson's group.

\begin{tabular}{cccc}
\hline Group of Robson & $\begin{array}{c}\text { Hospital Centres } \\
\text { Regional (CHR) }\end{array}$ & $\begin{array}{c}\text { University Hospital } \\
\text { Centres (CHU) }\end{array}$ & Average \\
\hline 1 & $8.1[5.08-10.2]$ & $6.7[3.3-10.82]$ & 7.4 \\
2 & $0.7[0-2.06]$ & $0.1[0.9-1.4]$ & 0.4 \\
3 & $9.5[5.27-11.39]$ & $6.3[4.4-7.2]$ & 7.9 \\
4 & $0.9[0-2.3]$ & $0.5[1-2.1]$ & 0.7 \\
5 & $5.8[3.2-7.5]$ & $8.1[5.5-15.75]$ & 6.9 \\
6 & $1[0.3-1.8]$ & $0.7[0.4-0.8]$ & 0.85 \\
7 & $1.4[0.6-2]$ & $0.2[0.06-1.4]$ & 0.8 \\
8 & $1.9[1.1-2.4]$ & $1.5[1.1-1.8]$ & 1.7 \\
9 & $1.3[0.9-2.2]$ & $0.1[0.35-2.1]$ & 0.7 \\
10 & $2.7[1.6-4.7]$ & $0.9[0.3-1.2]$ & 1.8 \\
Total & 33.3 & 25.1 & \\
\hline
\end{tabular}

[Extremes]. 
with a single term pregnancy in cephalic presentation (Groups 1 and 2) had a greater impact on overall CS, higher than the CS rate in women who had previously had a cesarean section (Group 5). Similar results have been reported by other researchers [16] [17] [18] [19] [20].

From our results, it was found that Groups 3, 1 and 5 were the largest contributors to the overall CS rate.

Multiparous women with a single term pregnancy in cephalic presentation, who have never had CS and who have had spontaneous labour (group 3) were the first group in importance. The contribution to the overall CS rate in this group was slightly higher than that of National Maternity Hospital in Dublin or in nine perinatal centres and lower than that of the medical system institutions in Latin America [18] [19] [21]. The CS rate in Group 3 is used as an indicator to assess the quality of data collection. If it is greater than $3 \%$, it is more likely to be due to the collection of inaccurate data or to indicate that the SC was performed in the absence of a medical reason.

Group 1 was the second most important in this study. In group 1 single-fetal nulliparous women, CS is generally performed for labour complications such as dystocia or fetal distress and the CS rate in this group should be relatively low. There is an opinion that intrapartum care of nulliparous women with fetuses in term cephalic presentation is a key indicator of obstetrical care in the delivery room [21]. In our study, the average CS rate in Group 1 was comparable to rates reported in other studies [16] [19] [21] [22]. However, significant variations between structures had been noted, clearly showing the great differences in obstetrical practice in Burkina Faso's hospital structures.

Group 5 was the third most important in this study. In this study, the CS rate in Group 5 was comparable to published rates in Latin America and higher than in other parts of the world [18] [19] [22]. Recent studies have shown that the size of this group is increasing and represents $11.3 \%$ to $18.8 \%$ of all women's deliveries [16] [19] [23] [24] [25] [26]. A large number of CSs in other groups, particularly in Groups 1 and 2, will inevitably increase. Group 5 and, since reducing CS in this group will likely be very difficult, this group will become even more important contributor to the overall CS rate. Therefore, the effort to reduce the overall CS rate should aim not only to increase vaginal deliveries after CS, but to avoid the first CS.

In the case of breech presentation, multiple pregnancies, abnormal premature deliveries (groups 6 to 10), the CS rate is likely to significantly exceed the average number of operations, but these groups are small and contribute relatively little to overall CS rates. In this study, CS in groups 6 - 10 accounted for one-fifth of the overall CS rate. Robson's classification has been used in a number of institutions and regions of the world over the past decade [16] [19] [20] [22] [23] [26] [27].

In this study, for the first time, we analyzed CS birth data from all medical institutions in Burkina Faso and identified the main groups of women who con- 
tributed most to the overall CS rate between 2017 and 2018. In addition, a significant variation in CS rates between different institutions was observed, especially among women with single term pregnancy in cephalic presentation without previous CS (Groups 1 to 4), showing large differences in country obstetric care.

We have provided ongoing educational assistance during the studies to avoid misclassification, but inaccurate data collection in some hospitals may occur. However, the unusually high CS rates in groups 1, 3 and 5 in some hospitals [24] [25] [27] [28] and significant variation in CS rates between different institutions, shows differences in obstetrical care and that CS was performed for potentially non-medical reasons. In an attempt to understand practices in some obstetrical groups, closer monitoring and analysis is needed and relevant in order to take effective actions to optimize CS rates. It appears that efforts to reduce the overall rate of CS should focus on increasing vaginal delivery after CS and reducing CS rates in nulliparous patients with a single term pregnancy in cephalic presentation (groups 1 and 2). In order to continue to monitor and analyze CS rates and to evaluate strategies to reduce CS rates, Robson's classification must be used continuously in all health facilities in Burkina Faso.

\section{Conclusion}

Women in groups 1, 3 and 5 were the most important contributors to the overall rate in Burkina Faso's hospitals. It seems that efforts to reduce the overall rate of CS should focus on increasing the number of deliveries to the scarred uterus and reducing CS rates among nulliparous women. This requires the creation of programmes and projects on the management of childbirth in primiparous women and on the management of uterine tests throughout the national territory.

\section{Conflicts of Interest}

The authors declare no conflicts of interest regarding the publication of this paper.

\section{References}

[1] World Health Organization (1985) Appropriate Technology for Birth. Lancet, 326, 436-437. https://doi.org/10.1016/S0140-6736(85)92750-3

[2] Organisation for Economic Co-Operation and Development (2011) Health at a Glance 2011: OECD Indicators. OECD Publishing, Paris. http://www.oecd.org/els/health-systems/49105858.pdf

[3] Ministère de la Santé du Burkina Faso (2017) Annuaire Statistique du Ministère de la Santé 2017. Ministère de la Santé du Burkina Faso, Ouagadougou, 156 p.

[4] British Columbia Perinatal Health Program (2009) Caesarean Birth Task Force Report 2008. Vancouver. http://www.powertopush.ca/wp-content/uploads/2010/05/CBTF_REPORT.pdf

[5] Hartmann, K.E., Andrews, J.C., Jerome, R.N., Lewis, R.M., Likis, F.E., McKoy, J.N., et al. (2012) Strategies to Reduce Cesarean Birth in Low-Risk Women. Agency for 
Healthcare Research and Quality, Rockville. http://www.ncbi.nlm.nih.gov/books/NBK114747/

[6] Lauer, J.A., Betran, A.P., Merialdi, M. and Wojdyla, D. (2010) Determinants of Caesarean Section Rates in Developed Countries: Supply, Demand and Opportunities for Control. World Health Report.

http://www.who.int/healthsystems/topics/financing/healthreport/29DeterminantsC -section.pdf

[7] Robson, M.S., Scudamore, I.W. and Walsh, S.M. (1996) Using the Medical Audit Cycle to Reduce Cesarean Section Rates. American Journal of Obstetrics \& Gynecology, 174, 199-205. https://doi.org/10.1016/S0002-9378(96)70394-0

[8] Thomas, J., Callwood, A., Brocklehurst, P. and Walker, J. (2000) The National Sentinel Caesarean Section Audit. BJOG: An International Journal of Obstetrics \& Gynaecology, 107, 579-580. https://doi.org/10.1111/j.1471-0528.2000.tb13296.x

[9] Robson, M. (2001) Classification of Caesarean Sections. Fetal and Maternal Medicine Review, 12, 23-39. https://doi.org/10.1017/S0965539501000122

[10] Torloni, M.R., Betran, A.P., Souza, J.P., Widmer, M., Allen, T., Gulmezoglu, M., et al. (2011) Classifications for Cesarean Section: A Systematic Review. PLoS ONE, 6, e14566. https://doi.org/10.1371/journal.pone.0014566

[11] Bolognani, C.V., Reis, L.B.dS.M., Dias, A. and Calderon, I.dM.P. (2018) Robson 10-Groups Classification System to Access C-Section in Two Public Hospitals of the Federal District/Brazil. PLoS ONE, 13, e0192997.

https://doi.org/10.1371/journal.pone.0192997

[12] Jasenko, F., Igor, H., Zlatan, F., Aida, Z. and Milorad, Z. (2016) Cesarean Section Rate. Analysis in University Hospital Tuzla-According to Robson's Classification. Medical Archives, 70, 213-216. https://doi.org/10.5455/medarh.2016.70.213-216

[13] Barčaitė, E., Kemeklienė, G., Railaitė, D.R., Bartusevičius, A., Maleckienè, L. and Nadišauskienė, R. (2015) Cesarean Section Rates in Lithuania Using Robson Ten Group Classification System. Medicina, 51, 280-285.

https://doi.org/10.1016/j.medici.2015.09.001

[14] Bartusevičius, A. and Barčaitè, E. (2007) Cezario pjūvio operacijų analizè remiantis M. Robsono klasifikacija [Analysis of Caesarean Section Deliveries Using Robson Classification]. Lietuvos akušerija ir ginekologija, 5, 108-113.

[15] Kraulaidytė, V., Puškova, I., Zakarevičienė, J., Juršènas, R., Laužikienė, D. and Ramašauskaite, D. (2011) Vilniaus miesto universitetinès ligoninès Akušerijos ir ginekologijos klinikoje atliktų cezario pjūvio operacijų analizè pagal M. Robsono klasifikaciją [Analysis of Caesarean Section Deliveries in the Year 2009 at the Clinic of Obstetrics and Gynecology of Vilnius City University Hospital Using Robson Classification]. Lietuvos akušerija ir ginekologija, 14, 114-121.

[16] Perinatal Services BC (2011) Examining Cesarean Delivery Rates in British Columbia Using the Robson Ten Classification. Part 1: Understanding the Ten Groups. Vancouver.

[17] Allen, V.M., Baskett, T.F. and O'Connell, C.M. (2010) Contribution of Select Maternal Groups to Temporal Trends in Rates of Caesarean Section. Journal of Obstetrics and Gynaecology Canada, 32, 633-641. https://doi.org/10.1016/S1701-2163(16)34566-2

[18] Betran, A.P., Gulmezoglu, A.M., Robson, M., Merialdi, M., Souza, J.P., Wojdyla, D., et al. (2009) WHO Global Survey on Maternal and Perinatal Health in Latin America: Classifying Caesarean Sections. Reproductive Health, 6, Article No. 18. https://doi.org/10.1186/1742-4755-6-18 
[19] Brennan, D.J., Robson, M.S., Murphy, M. and O’Herlihy, C. (2009) Comparative Analysis of International Cesarean Delivery Rates Using 10-Group Classification Identifies Significant Variation in Spontaneous labor. American Journal of Obstetrics and Gynecology, 201, 308.E1-308.E8. https://doi.org/10.1016/j.ajog.2009.06.021

[20] Chong, C., Su, L.L. and Biswas, A. (2012) Changing Trends of Cesarean Section Births by the Robson Ten Group Classification in a Tertiary Teaching Hospital. Acta Obstetricia et Gynecologica Scandinavica, 91, 1422-1427. https://doi.org/10.1111/j.1600-0412.2012.01529.x

[21] Brennan, D.J. and Robson, M. (2009) Nulliparous Term Singleton Vertex Caesarean Delivery Rates. American Journal of Obstetrics and Gynecology, 200, e8. https://doi.org/10.1016/j.ajog.2008.09.004

[22] Robson, M. (2011) National Maternity Hospital Dublin. Labour and Delivery Summary for the Year 2010. National Maternity Hospital, Dublin.

[23] McCarthy, F.P., Rigg, L., Cady, L. and Cullinane, F. (2007) A New Way of Looking at Caesarean Section Births. Australian and New Zealand Journal of Obstetrics and Gynaecology, 47, 316-320. https://doi.org/10.1111/j.1479-828X.2007.00753.x

[24] Brennan, D.J., Murphy, M., Robson, M.S. and O’Herlihy, C. (2011) The Singleton, Cephalic, Nulliparous Woman after 36 Weeks of Gestation: Contribution to Overall Cesarean Delivery Rates. Obstetrics \& Gynecology, 117, 273-279. https://doi.org/10.1097/AOG.0b013e318204521a

[25] Stavrou, E.P., Ford, J.B., Shand, A.W., Morris, J.M. and Roberts, C.L. (2011) Epidemiology and Trends for Caesarean Section Births in New South Wales, Australia: A Population-Based Study. BMC Pregnancy Childbirth, 11, Article No. 8. https://doi.org/10.1186/1471-2393-11-8

[26] Howell, S., Johnston, T. and Macleod, S.L. (2009) Trends and Determinants of Caesarean Sections Births in Queensland, 1997-2006. Australian and New Zealand Journal of Obstetrics and Gynaecology, 49, 606-611. https://doi.org/10.1111/j.1479-828X.2009.01100.x

[27] Kelly, S., Sprague, A., Fell, D.B., Murphy, P., Aelicks, N., Guo, Y., et al. (2013) Examining Caesarean Section Rates in Canada Using the Robson Classification System. Journal of Obstetrics and Gynaecology Canada, 35, 206-214. https://doi.org/10.1016/S1701-2163(15)30992-0

[28] Robson, M., Hartigan, L. and Murphy, M. (2013) Methods of Achieving and Maintaining an Appropriate Caesarean Section Rate. Best Practice \& Research Clinical Obstetrics \& Gynaecology, 27, 297-308. https://doi.org/10.1016/j.bpobgyn.2012.09.004 